\title{
Placing Darwin into the heart of the Natural History Museum
}

\author{
Robert M. Bloomfield
}

Published online: 14 April 2012

(C) Springer Science+Business Media, LLC 2012

\begin{abstract}
In 2009, the Natural History Museum, London celebrated the bicentenary of Charles Darwin and the sesquicentennial of his seminal work The Origin of Species by Means of Natural Section by commissioning a new contemporary artwork as a permanent insertion into the famous grade one listed
\end{abstract}

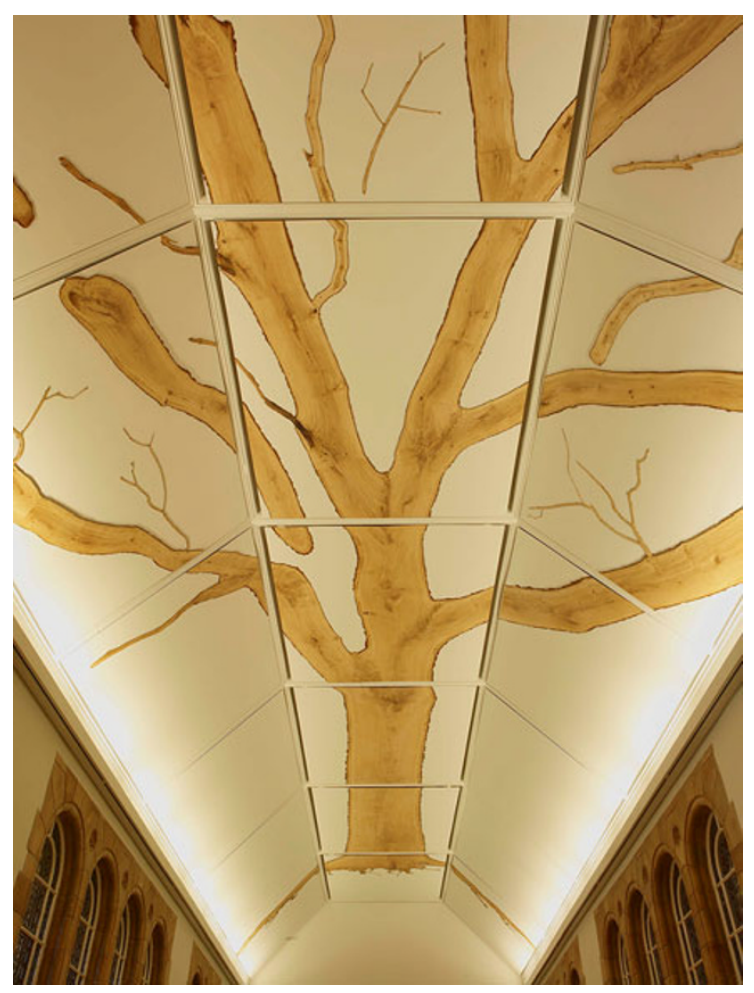

TREE by Tania Kovats, commissioned by the Natural History Museum to celebrate the 200 anniversary of Charles Darwin. Printed by permission of the Natural History Museum

R. M. Bloomfield $(\bowtie)$

Natural History Museum, London,

London, UK

e-mail: r.bloomfield@nhm.ac.uk
Waterhouse architecture in South Kensington. This article explores the motivation and delivery of this extraordinary work and its deeper message for today and tomorrow.

Keywords Evolution - Charles Darwin · On the Origin of Species by Means of Natural Selection · Natural History Museum $\cdot$ Contemporary art $\cdot$ Art $\cdot$ Science

\section{Summary}

In 2009, the Natural History Museum, London celebrated the bicentenary of Charles Darwin and the sesquicentennial of his seminal work The Origin of Species by Means of Natural Section by commissioning a new contemporary artwork as a permanent insertion into the famous grade one listed Waterhouse architecture in South Kensington. This article explores the motivation and delivery of this extraordinary work and its deeper message for today and tomorrow.

Charles Darwin was one of a last generation of gentleman scientists. The late nineteenth century saw the emergence of a profession of science through efforts typified by Darwin's bulldog Thomas Henry Huxley. Following in this path, natural history museums increasingly codified themselves as science research organizations specializing in systematic science. Their collections have quite rightly become seen in toto as "models of the diversity of the natural world" and (for example) have become highly significant in understanding contemporary science questions such as understanding biodiversity (and the implications of its loss). However, this focus on the scientific value of natural history collections has tended to leave other aspects of their significance to one side. For example, the practice of collecting reflects sociopolitical history; many of the major natural history museums grew as exercises in projecting the prestige of empire while collecting was often driven as much by economic interests as by sciencesomething particularly evident in the botanical search for new 
economic plants. Collecting in the past was also often in the context of ethical values that would be regarded as dubious today: specimens collected without any consideration of who has any customary right to them or to whom might benefit from their exploitation. These are questions that museums now face as international collecting and research agreements hinge on the sensitive issue of access and benefit sharing around the exploitation of natural resources.

In the past decade, there has been a noticeable emergence of "new perspectives" reconsidering the wider significance of collections, the nature of the knowledge they hold and to whom this is relevant. The Natural History Museum, has been encouraging others to explore the significance of the collections from their perspective and practice; and one aspect of this has been working with contemporary artists. In 2006, the museum considered its response to the pending 2009 celebrations of Charles Darwin. His work and achievements would also, inevitably, be reevaluated in a wider context than just his immediate impact on the understanding of science. Darwin's work was not just that of a meticulous collator, researcher, and synthesizer of evidence; nor was it just that of a brilliant mind which crystallized a new paradigm that would lead to the emergence of entire new areas of science such as those we now call ecology, evolutionary biology, and animal behavior. Darwin is also seen in the wider context; how his ideas challenged contemporary understanding of the nature of the world and of human origins (and continue to); how his science was perhaps not entirely value-free; and how its direction may well have been influenced by deep ethical values, such as his and his family's abhorrence of slavery and their belief in the equality of humankind. Inevitably, as the Natural History Museum looked toward a fitting celebration of Darwin's achievements, it sought to take a wider perspective and to seek a means of marking the celebrations in a lasting way that would also reflect how museums are reconsidering their roles in the new millennium.

By late 2006, the Natural History Museum had recognized the importance of 2009 as a time not only to celebrate the bicentenary of Charles Darwin's birth, but also, as it coincided with the 150th anniversary of the publication of The Origin of Species by Means of Natural Section, a time to reinforce the contemporary relevance of Darwin's work and to reinforce how, over the intervening years a vast accumulation of evidence from many disciplines meant that confidence in the mechanism of evolution has grown ever more robust.

The history of the Natural History Museum in London is entangled with the emergence of Darwin's ideas. It was the museum's first superintendent, the eminent anatomist Richard Owen, who after the publication of The Origin of Species by Means of Natural Section the previous November, had provided Samuel Wilberforce with the arguments to try and oppose "Darwin's bulldog," Thomas H. Huxley, at the British Association for the Advancement of Science meeting in Oxford in 1860.
It was Owen who also championed the move to house what were the British Museum's natural history collections in a new building in South Kensington. When he briefed the then newly emerging architect appointed for the work, Alfred Waterhouse, Owen stipulated, 20 years after the publication of The Origin of Species by Means of Natural Section, that the building should celebrate the wonder and awe of creation. When the building eventually opened to the public in 1881 , its inspiration had come from Romanesque cathedrals. Its terracotta facade was richly decorated with motifs inspired by specimens from the collections. These were presented so that the western galleries were decorated with living forms, while depictions of creatures from the extinct past were evident on the eastern side.

When it opened, the press reported how the heart of the museum, a cathedral-like central hall, inspired a great sense of reverence. Its columns, like the trunks of vast trees, reached up to support a barrel ceiling supported by the branches of iron girders. The panels of the ceiling were painted and gilded with important economic plants.

The museum's first director, the successor to Owen, William Flower, was convinced by Darwin's theories, and it was under his auspices that on Darwin's death, a large Portland stone sculpture of a seated Darwin was placed on the grand staircase of this hall (Fig. 1). Later, on Owen's death, a bronze of the First Superintendent was placed in the central position while the relegated Darwin stature was placed in the rear hall. The Owen statue remained on the landing of the grand staircase until the summer of 2008. When it was time to celebrate Darwin's work in 2009, the museum's trustees accepted two proposals. The first was to recognize the central significance of Darwin's contribution to science by returning the statue of Darwin to its central position of preeminence. In March 2009, in advance of the bicentenary celebrations hosted by the museum on February 12, the Darwin statue was returned to its rightful place. This was highly symbolic as a confirmation of the museum's confidence in the evolutionary synthesis which has emerged over the intervening years.

The second proposal accepted by trustees concerned the room directly behind this staircase on the mezzanine level. This is an inner "chapel" gallery that connects between the east and west balconies. This had also originally been decorated with an illuminated ceiling - long destroyed by interventions in the 1950-1960s when this space had been converted into a kitchen-cafe. While this beautiful space with its barn-vault ceiling and stained glass fenestration featuring floral motifs had since been restored, the ceiling panels had been left in plain white.

This second proposal was more ambitious. It was to create a contemporary response to the museum architecture - using the ceiling of the restored mezzanine "chapel" to honor Darwin.

As a grade one listed building, this would need careful attention, and from the summer of 2007, consultations began with interested parties including local planning authorities and 
Fig. 1 For a period after Darwin's death, his stone statue graced the museum's stepslooked on by the bronze statue of Owen (left foreground). On Owen's death, his statue took center stage and Darwin's was placed in a rear gallery (circa 1883) (Published with permission and copyright of Natural History Museum)

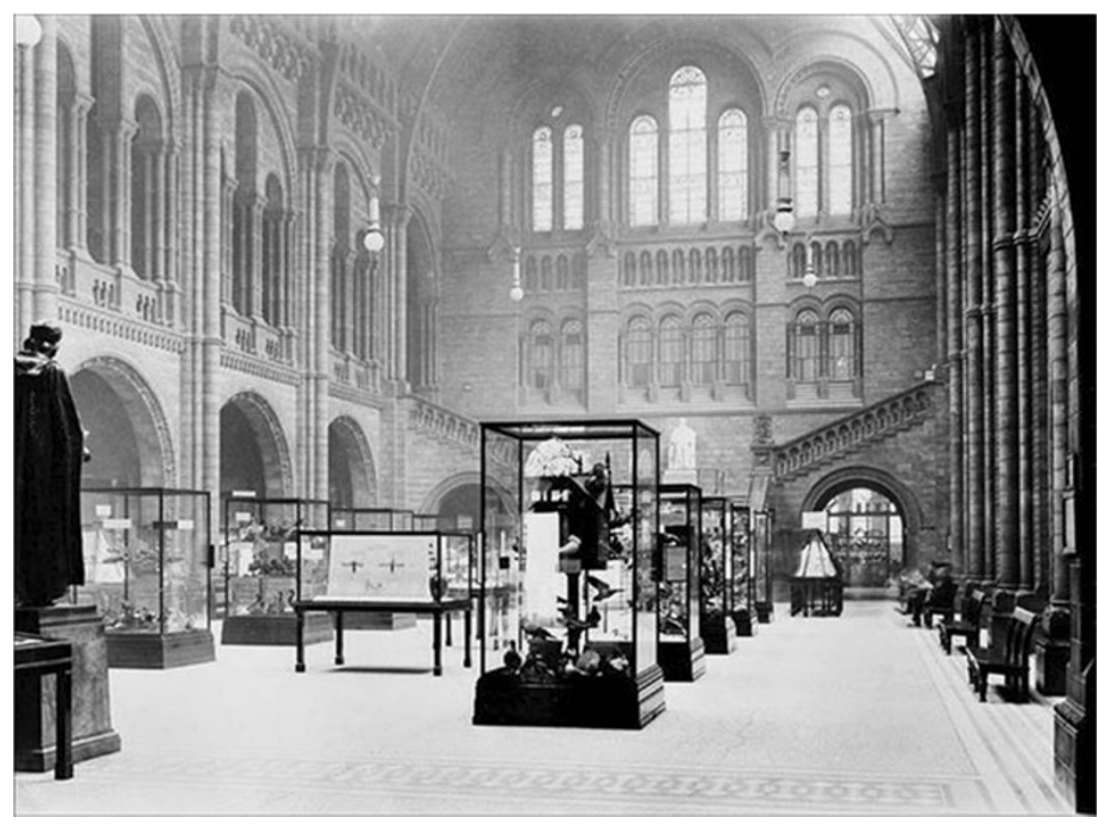

English Heritage, the UK organisation with responsibility for preserving listed buildings. A key to the work would be an appropriate, site-specific response to the importance of Darwin's ideas.

In the early autumn of 2007, the Natural History Museum invited 17 leading UK curators and critics of the contemporary arts to propose artists who might fulfill the challenge. From their proposals, 40 artists were placed on a long list-all of whom had been approached and were, in principle, interested in a competition for the commission. Later, a panel of art experts, museum experts, and scientists met at the museum. They reduced the field to a short list of ten artists - on the basis of their previous work, interests, and practice; and therefore, their potential sensitivity to creating this work. Among them were two previous Turner Prize winners and other Turner Prize nominees. Each of the ten artists agreed to prepare a concept proposal for which they would receive a nominal fee. These were exhibited in a public exhibition hosted at the museum in the summer of 2008. The exhibition, "Darwin's Canopy," curated by the museum's contemporary art curator Bergit Arends, encouraged visitors to offer views on the submitted proposals - which were taken into account when the selection panel reconvened to see the works and decide which one to take forward to the final commission.

The work chosen by a unanimous decision of the panel was TREE, a proposal by artist Tania Kovats. Kovats was immersed in Darwin's ideas, evidenced by the fact that she had to submit her entry electronically from South America where she was already on a journey retracing Darwin's footsteps armed with The Beagle Narratives as her guide.

Her proposal was deceptively simple, inspired by Darwin's iconic sketch of a branching diagram of relationships in his Transmutation Notebook B, next to which he had famously jotted "I think." This is generally regarded as a critical point in the emergence of Darwin's own understanding-when he realised that species were not separated but were interrelated over time, which would lead to an ever-branching evolutionary tree. However, her idea of manifesting this was nothing if not ambitious. She wanted to respond to: the museum's core role of housing research collections, the cross-section of the giant Sequoia - a historical gift to the Museum from the United States that had long adorned the upper balcony of the main hall, the decorated ceiling of botanical images, and to the process of science research-Darwin himself had taken a microscope on the Beagle and had prepared a slide collection. All these ideas merged in Kovats' proposition to embed into the ceiling a vast longitudinal, wafer-thin section through an entire 200-year-old English oak tree. This would respond to the historic bicentenary, as the tree's growth is analogous to that of the understanding in evolutionary biology from Darwin's acorn over a similar time scale. The longitudinal section would become one of the museum's largest accessioned specimens as well as having symmetry with the historical Sequoia specimen across the hall. The work would be an intimate, though entirely contemporary, response to the original decorative intention of Waterhouse's ceilings.

While the idea was simple and profound, its creation would be a monumental task. The tree could not be procured until September, 2008 as the sap began to recede and the leaves then fall. It would require a hugely mapped exercise for expert tree surgeons to dissect a 21-meter tree into sections that could later be reconstructed. A hugely technical effort involving large-scale kiln-drying of the timber would have to be undertaken against a tight deadline - and the project would rest on the quality of this curing. A novel way of employing anodized aluminium panels and specialized 
resin-bonding would have to be devised to support the three- to five-millimeter-thick sections which Kovats wanted to achieve so they would have the rigidity and structural capacity to be incorporated into the ceiling.

Then there were ethical issues; simply destroying a tree for the work was insupportable. The museum is deeply aware of how Darwin's ideas underpin our contemporary understanding of ecology and biodiversity; and today, biodiversity is in peril and the future of humans and the natural world faces a pending human-induced mass extinction. We wanted the work to respond to this, and to the need for humans to take a much more enlightened approach to our complex evolved world, and to the need for sustainable use of natural resources.

Having chosen the work, the museum approached the Longleat Estate of Lord Bath in Wiltshire. The estate includes large tracts of broadleaf forest, which are both commercially managed and recognized as a designated Site of Special Scientific Interest (SSSI) because of their biodiversity. Here, a tree could be chosen as part of the usual timber crop, but it would be in the context of high-level sustainable forestry practice. While the estate primarily uses long-term natural succession to replace its cut timber, which encourages native tree diversity, we agreed with them to plant 200 young oak trees on areas of the estate as "Darwin clumps" where remedial restoration and amity trees were being planned. It would also be highly unusual for the estate to extract the 20-ton tree stump that this work required. This would provide the opportunity to excavate a massive hole and create from this a pond within the forest - a habitat that was scarce on the estate. All of this work would be captured and recorded in a video installation that would record the creation of the work and comment on sustainable practices which both supported the rural economy and encouraged biodiversity. The museum collected samples of the tree and conducted a survey of invertebrates that were accessioned into the botany and entomology collections. As a final part of the work, a limited series of sections of a branch - taken from the same tree-were created into set of works called BRANCH, one of which was gifted to museums in each country visited by Darwin's Beagle as a goodwill gift to commemorate Darwin's life and work.

TREE was opened in March 2009 by the UK Minster of Culture the Rt. Hon. Barbara Follett in the immediate aftermath of the February birthday celebrations. TREE, beautifully proportioned across the 18 panels of the ceiling, is an inspirational reminder that all life shares a common origin in the roots of evolution. Rendered in stalwart English oak, it is a metaphor of the endurance of Darwin's ideas, as well as Darwin's own bravery and commitment to them.

Kovats' work is both simple and profound, and there lies its achievement as a contemporary contribution to the historical Waterhouse's building, which will be visible in the future century. Then people may consider this work in the light of our current time. It will reflect how people of the early twentyfirst century responded to the evidence of evolution, to the issues of biodiversity loss and environmental change, and to the challenge of finding a more equitable path of sustainable development within our evolved world. Of course, part of the work will be those trees which survive to mature at Longleat, recorded on their estate maps, and hopefully continuing to support biodiversity and reminding people of these critical decades faced by humans and the natural world.

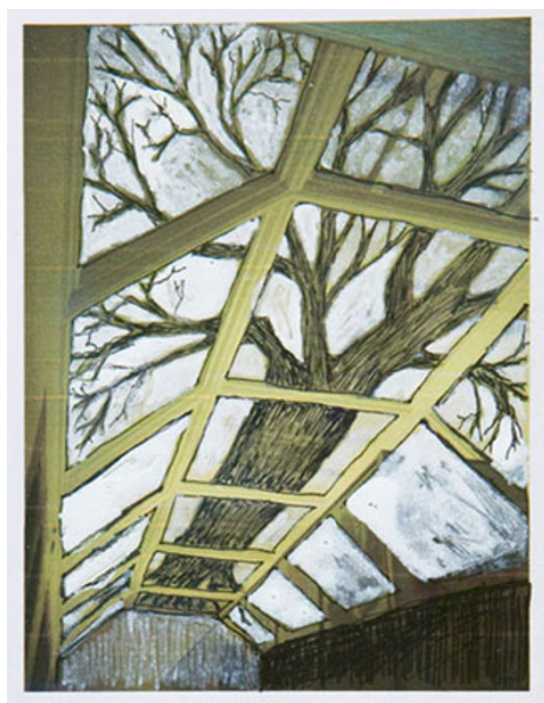

Initial artist's concept - a 200-year-old oak tree - one for each of Darwin's years: oak for England and for the strength and resolution of his ideas, laminated over the 18 panels of the Waterhouse inner sanctum ceiling

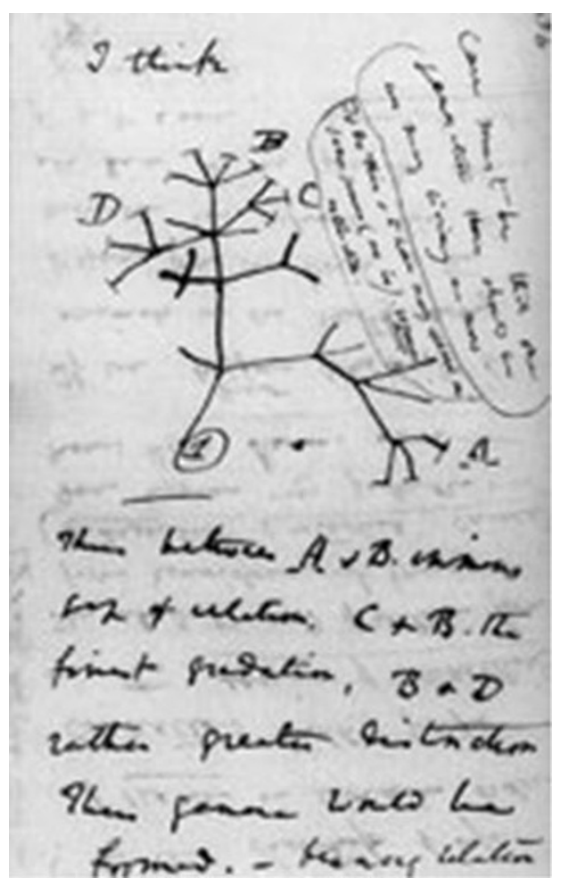

Darwin's original sketch from Transmutation Notebook B, root of the artist's inspiration 


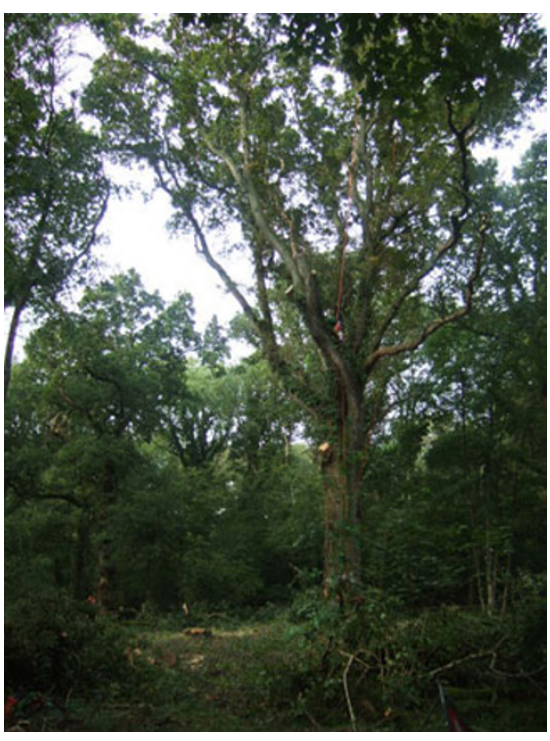

The oak tree being taken from the SSSI biodiversity forest on Longleat Estate

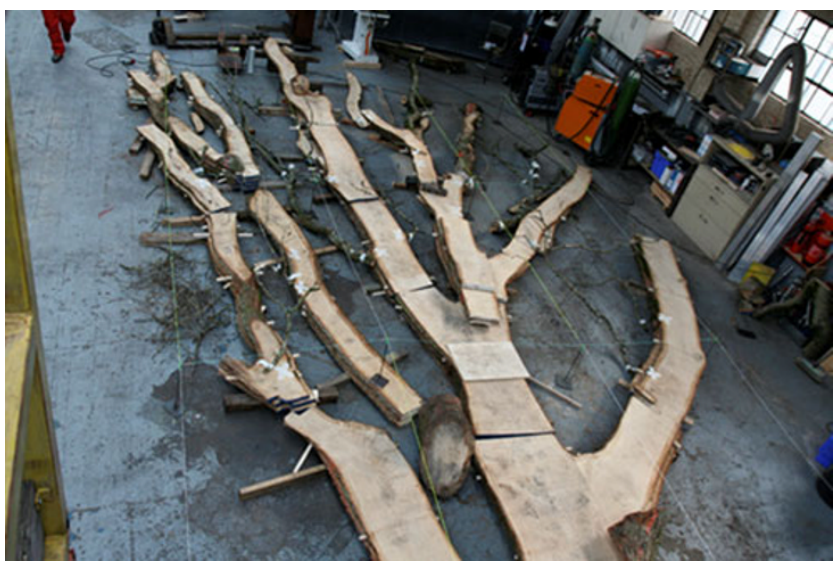

"Tree"- the planked sections being roughly assembled prior to kiln-drying (CMike Smith Studio)

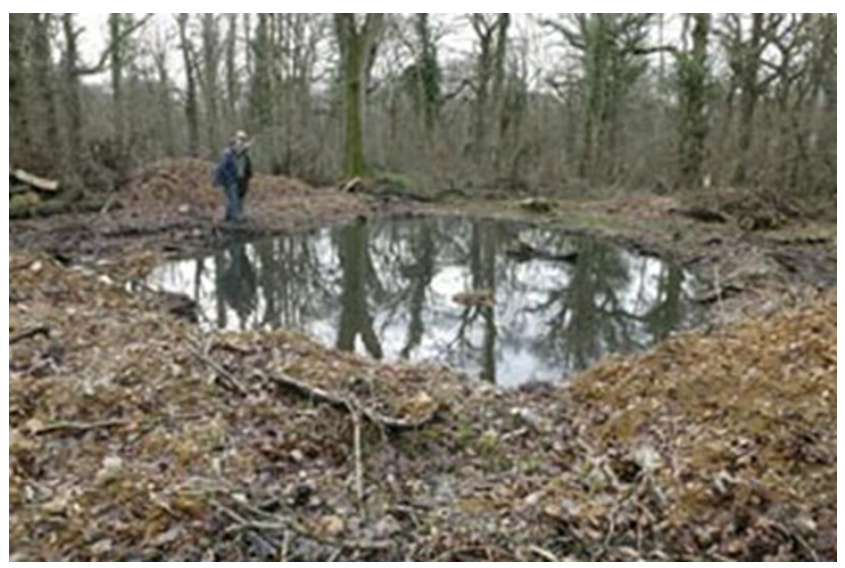

Biodiversity pool being developed at the site where the 10-ton root ball was excavated for the work

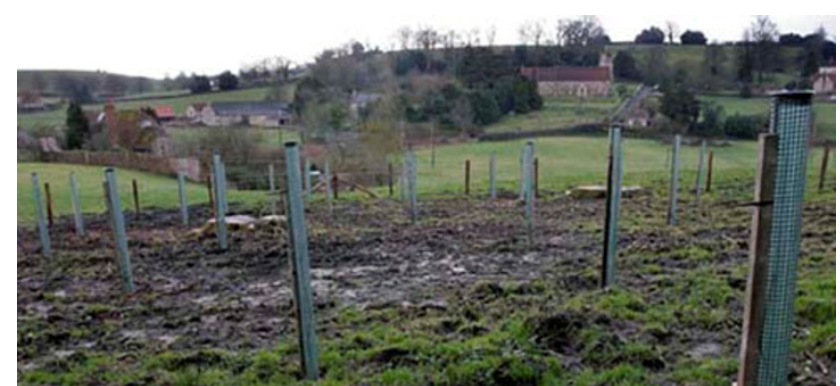

Two hundred 3-year-old oak trees planted in the Darwin Clumps as part of the work

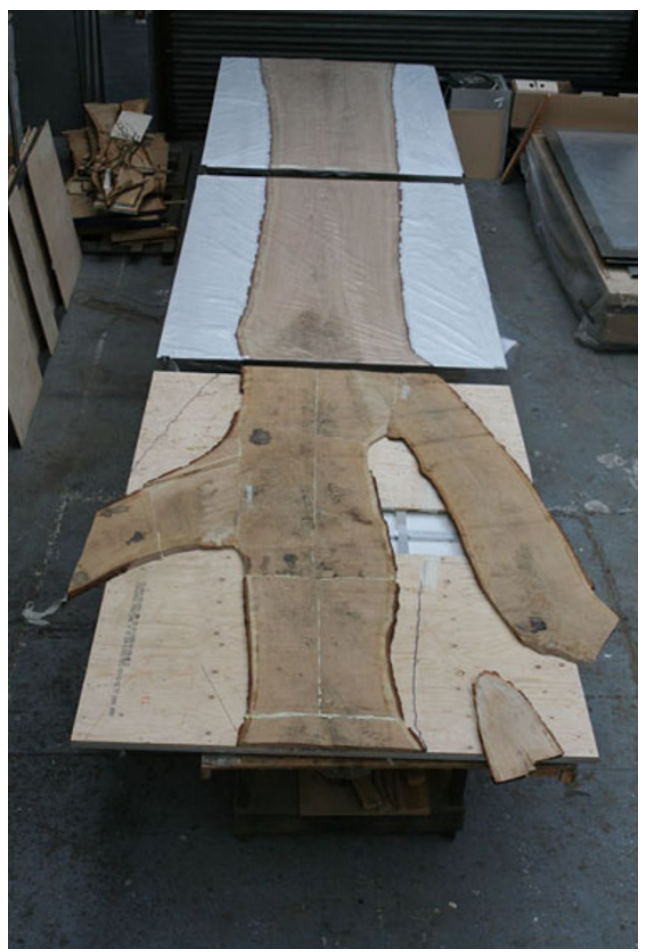

Ceiling sections being prepared at the fabricator's studio. Kiln-dried planks bonded to aluminium honeycomb sheets routed to 3-mm-thin veneers (CMike Smith Studio)

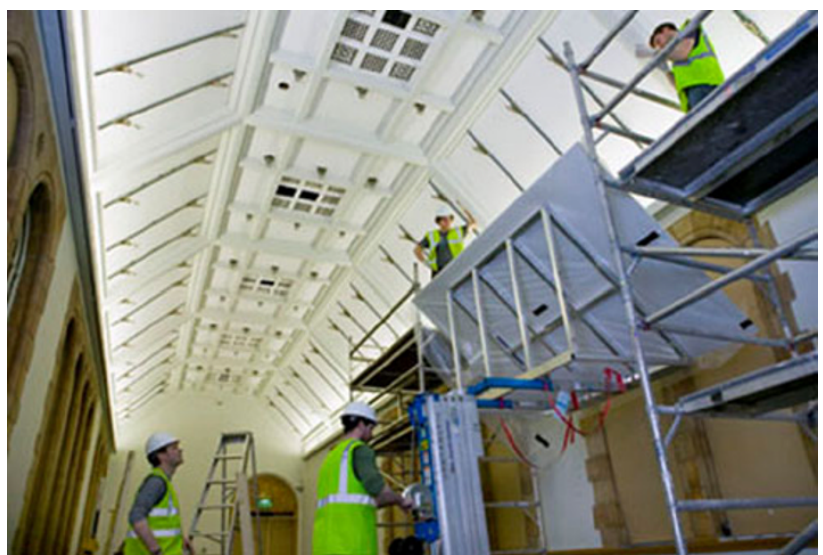

The newly refurbished gallery with ceiling armatures for the 18 panels in place: receiving the first panel 